\title{
Minutea Object Extraction in Fingerprint Image Using Morphological Methods and Gabor Filters \\ (Ekstraksi Objek Minutea Pada Citra Sidik Jari Dengan Metode Morfologi dan Gabor Filter) \\ Julius Santony \\ Universitas Putra Indonesia "YPTK" Padang, Indonesia \\ juliussantony@yahoo.co.id
}

\begin{abstract}
Abstrak
Minutiae merupakan bagian pada sidik jari yang merupakan titik dimana garis sidik jari berhenti atau bercabang, yang dapat diamati dengan pemindaian pada resolusi 500 ppi. Sidik jari seseorang rata-rata memiliki minutiae yang berkisar 50-100 buah dan tersebar di seluruh permukaan sidik jari. Untuk dapat melihat sebuah sidik jari dengan jelas maka dapat dilakukan dengan mengekstrak minutiae yang terdapat pada sidik jari tersebut. Dengan proses ekstraksi ini maka citra sidik jari yang awalnya kurang jelas maka dapat diperjelas, sehingga identifikasi terhadap sebuah sidik jari akan mudah untuk dilakukan. Pada penelitian ini dilakukan ekstraksi objek minutiae pada citra sidik jari, supaya objek garis sidik jari dapat dilihat dengan jelas. Tahapan penelitian yang dilakukan pada citra sidik jari adalah deteksi objek dan deteksi tepi dengan metodemorfologi. Tahap berikutnya ekstraksi objekminutiae dengan proses gabor filter dan minutiae extraction. Hasil yang dicapai menunjukan bahwa ekstraksi objek minutea dapat menampilkan garis sidik jari citra sidik jari dengan jelas. Dari hasil pengujian 10 citra sidik jari terbukti bahwa objekminutiaeyang ada pada citra dapat diekstraksi, sehingga garis sidik jari citra hasil lebih jelas dibandingkan dengan citra asli.
\end{abstract}

Kata kunci:Minutiae,sidik jari, ekstraksi, morfologi, gabor filter

\begin{abstract}
Minutiae is part of the fingerprint, which is the point where the fingerprint line stops or branches, which can be observed by scanning at a resolution of $500 \mathrm{pp}$. a fingerprint has minutiae that range from 50-100 pieces scattered throughout the surface of the fingerprint. To clarify the fingerprint can be done by extracting the minutiae contained in the fingerprint. With this extraction process, fingerprint images can be clarified, so identification of a fingerprint will be easy to do. This research extracts minutiae objects in the fingerprint image, so that the fingerprint line object can be seen clearly. The first stage in this research is object detection and edge detection using morphological methods. The next step is the extraction of minutiae objects with the gabor filter and minutiae extraction. The results obtained can display the fingerprint line of the fingerprint image clearly. From the results of testing 10 fingerprint images proved that the minutiae object in the image can be extracted, so that the fingerprint line of the image is clearer than the original image.
\end{abstract}

Keywords: Minutiae, fingerprint, extraction, morphological, gabor filter

\section{Pendahuluan}

Sidik jari adalah suatu bentuk pola garis (ridge) pada permukanan ujung jari. Suatu sidik jari berkualitas baik, dilihat berdasarkan pola-polasidik jarinya [1]. Pola sidik jari mengikuti klasifikasi yang dibuat oleh Sir Edward Henry dan Sir Francis Galton pada tahun 1892-1897. Untuk mengidentifikasi sidik jari seseorang, maka diperlukan sebuah sistem pengenalan sidik jari [2]. Sistem pengenalan sidik jari dinamakan biometrik yang merupakan teknologi pengenalan diri dengan karakteristik alami manusia[3]. Sistem biometrik dapat digunakan untuk mengidentifikasi sidik jari dari jumlah lekukan, jenis, arah, lokasi kunci dari titik yang adadan lokasi dari pori-pori pada jari. Mengingat simpel serta luasnya penggunaan teknologi ini, pemindaian sidik jari merupakan teknologi biometrik yang paling banyak digunakan saat ini. Alat yang digunakan untuk memindai sidik jari adalah scaner sehingga dapat menghasilkan citra sidik jari [4]. Kendala yang sering dijumpai dari hasil scan citra sidik jari yang diambil, mempunyai kualitasyang rendah [5].Hal ini disebabkan antara lain karena citra sidik jari berminyak, citra sidik jari kering dan citra sidik jari kotor. Ketiga faktor ini menyebabkan rigde ending 
(garis terputus) dan bifurcation (dua garis yang bertemu di salah satu ujungnya) sehingga bisa mempengaruhi nilai titikdari garis citra sidik jari (minutiae)[6]. Kualitas citra sidik jari yang rendah menyebabkan sidik jari sulit utuk dikenali, Untuk meningkatkan kualitasnya, dapat dilakukan dengan mencari nilai minutiae yang tepat dengan Metode Morfologi dan Metode Gabor Filter. Penelitian tentang citra sidik jari yang pernah dilakukan sebelumnya adalah ekstraksi citra sidik jari dengan tahapan binerisasi, segmentasi dan penepisan citra yang dapat menetapkan validitas untuk titik minutiae. Penelitian selanjutnya, ekstraksi sidik jari untuk penghapusan minutiae palsu dari hasil proses binerisasi dan penipisan citra. Hasil yang didapat adalah dapat membedakan minutiae asli dengan yang palsu, sehingga nilai minutiae yang palsu dihilangkan dan minutiae yang asli diperjelas.

\section{Tinjauan Literatur}

Sidik jari adalah suatu bentuk pola garis (ridge) pada permukanan ujung jari []].Klasifikasi pola sidik jari didasarkan ciri-ciri visual yang dimiliki setiap sidik jari, yaitu arah alur(ridge),titik pusat(core), dan pertigaan (delta) []].

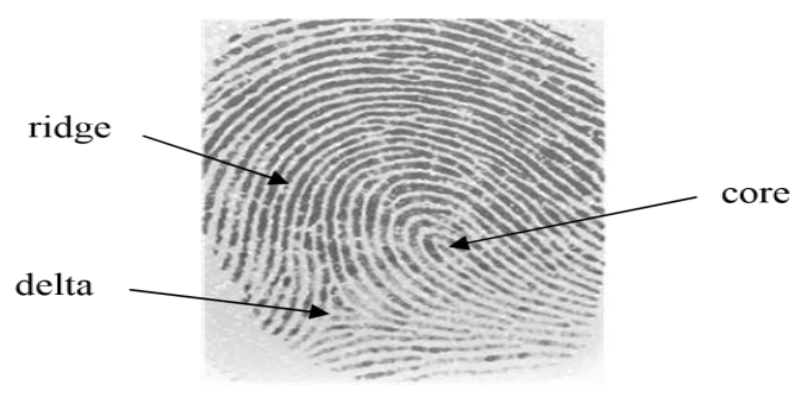

Gambar 1:Klasifikasi Pola Sidik Jari

Morfologiadalah pendekatan berbasistopologidan bentuk geometriuntukmelakukananalisispadacitra, salah satunya adalah citra sidik jari [9]. Operasi morfologi merupakan operasi yang umum dikenakan pada citra biner (hitam-putih) untuk mengubah struktur bentuk objek yang terkandung dalam citra [10].Selain pada citra biner operasi morfologi sesungguhnya juga dapat dikenakan pada citra tingkat keabuan. Gabor filter dikembangkan untuk mensimulasikan kemampuan visual manusia dalam mengamati tekstur benda [11]. Fungsi Gabor ditemukan oleh Dennis Gabor pada tahun 1946 yang semula didefiniskan tetapi dikembangkan oleh John Daugman pada tahun 1980 Complex. Gabor Filterdapat diterapkan pada citra sidik jari secara spasial pada konvolusi citra dengan filter.

\section{Metodologi}

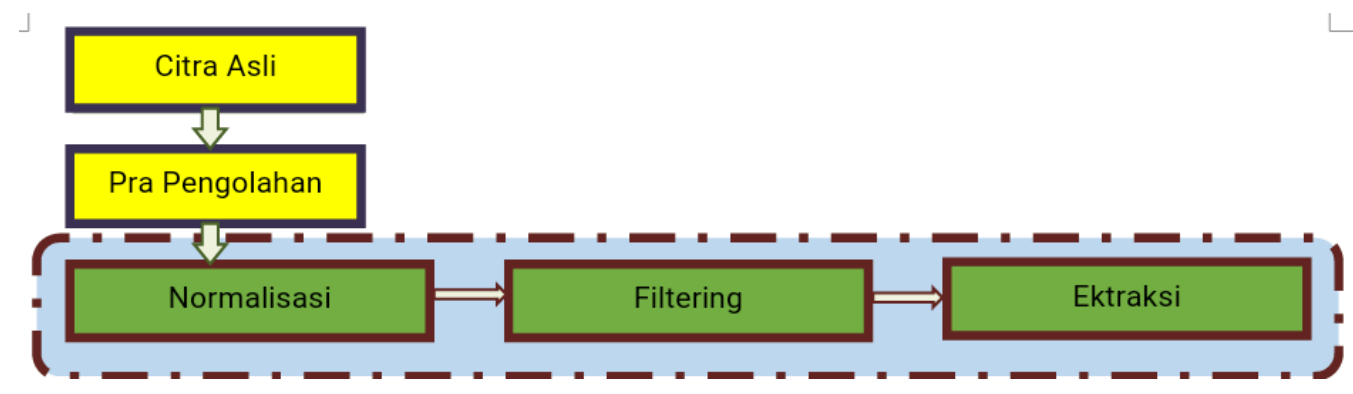

Gambar 2: Tahapan Penelitian 
Berdasarkan Gambar 2 maka terdapat 5 tahapan pada penelitian ini, yaitu :

1. Tahap pertama adalah pengumpulan data citra sidik jari dari hasil scanning

2. Tahap kedua adalah pra pengolahan berupa proses cropping yaitu dengan cara memotong citrasidik jari sehingga dapat menghilangkan informasi-informasi lain yang dapat dianggap sebagai noise yang berada diluar area lokasi objek yang akan diteliti.
Algoritma 1. Algoritma Cropping
1. Baca data citra asli
2. Tampilkan citra asli
3. Tentukan ukuran citra
4. Tentukan titik sudut kanan atas dan titik sudut kanan bawah
5. Cropping citra sidik jari berdasarkan titik sudut yang telah ditentukan
6. Tampilkan citra yang telah di-cropping
7. Simpan citra cropping

3. Tahap ketiga adalah proses normalisasi. Normalisasi bertujuan untuk meratakan nilai intensitas dengan menggunakan metode morfologi, sehingga objek dan tepi objek dapat dideteksi.Citramasukan berupacitra grayscalediolahdenganmorfologi dilasi dan morfologi erosi sehingga mampu mendeteksi objek yang ada pada citra sidik jari, termasuk objek minutiae.
Algoritma 2. Algoritma Normalisasi
1. Baca citra hasil cropping
2. Tampilkan citra cropping
3. Tentukan elemen pembentuk struktur untuk proses morfologi
4. Lakukan proses morfologi dilasi dari citra cropping
5. Lakukan proses morfologi erosi dari citra cropping
6. Kurangkan morfologi dilasi dan morfologi erosi untuk normalisai
7. Tampilkan hasil proses morfologi dilasi
8. Tampilkan hasil proses morfologi erosi
9. Tampilkan citra hasil normalisasi
10. Simpan citra hasil proses morfologi dilasi
11. Simpan citra hasil proses morfologi erosi
12. Simpan citra hasil proses normalisasi

4. Tahap ke empat adalah proses filtering. Pada tahap ini citra yang sudah ternormalisasi dilakukan prosesfiltering dengangabor filter untuk menghasilkan 8 citra sidik jari. Pada tahap ini citra sudah ternormalisasi dilakukan proses gabor filter untuk menghasilkan 8 citra sidik jari. Prose filter gabor menggunakan 8 arah orientasi yang berbeda, yaitu : $0^{\circ}, 22.5^{\circ}, 45^{\circ}, 67.5^{\circ}, 90^{\circ}, 112.5^{\circ}, 135^{\circ}, 157.5^{\circ}$.
Algoritma 3. Algoritma Filtering
1. Baca citra hasil normalisasi
2. Tampilkan citra normalisasi
3. Tentukan nilai untuk prosesGabor Filter dengan ukuran 32x32 dan orientasi (0:22.5:180-22.5).
4. Lakukan proses garbor sebanyak jumlah nilai orintasi yang pada langkah 3
5. Tampilkan citra hasil filtering
6. Simpan citra hasil proses filtering 
5. Tahap ke lima adalah proses ekstraksi. Pada tahap ini citra yang sudah melalui tahapan filtering, akan diekstrak. Sebelum diekstrak dilakukan proses penggabungan citra hasil dari filtering, kemudian proses binerisasi dan selanjutnya thinning. Untuk proses binerisasi dilakukan dengan nilai threshold 150 . Untuk proses thinning, didasarkan pada transformasi hit-missdengan bertujuan untuk menghitung struktur seri.

\section{Algoritma 4. Algoritma Penggabungan}

1. Baca citra hasil filtering yaitu citra Gabor Filter $0^{\circ}$, Citra Gabor Filter $22.5^{\circ}$, Citra Gabor Filter45 ${ }^{\circ}$, Citra Gabor Filter67.5, Citra Gabor Filter $90^{\circ}$, Citra Gabor Filter $112.5^{\circ}$, Citra Gabor Filter $135^{\circ}$ dan Citra Gabor Filter $157.5^{\circ}$

2. Gabung ke delapan citra

3. Tampilkan citra hasil penggabungan

4. Simpan citra hasil penggabungan

\section{Algoritma 5. Algoritma Binerisasi}

1. Baca citra hasil penggabungan

2. Tampilkan citra hasil penggabungan

3. Lakukan proses merubah citra menjadi biner

4. Tampilkan citra hasil binerisasi

5. Simpan citra hasil binerisasi

\section{Algoritma 6. Algoritma Thining}

1. Baca citra hasil binerisasi

2. Tampilkan citra hasil binerisasi

3. Lakukan proses thinning

4. Tampilkan citra hasil thining

5. Simpan citra hasil thining

\section{Algoritma 7. Algoritma Ekstraksi}

1. Baca citra hasil thining

2. Tampilkan citra hasil thining

3. Tentukan ukuran citra hasil thining

4. Lakukan proses ekstraksi denganminutiae extraction untuk menghasilkan rigde ending

5. Lakukan proses ekstraksi dengan minutiae extractionuntuk menghasilkan bifurcation

6. Tampilkan citra hasil ekstraksi

7. Simpan citra hasil ekstraksi

\section{Hasil dan Diskusi}

Setiap langkah dari proses yang dilakukan berdasarkan metodologi penelitian diimplementasikan dengan Bahasa Pemrogramam Matlab, dan menghasilkan output yang berbeda-beda untuk dapat mencapai tujuan dalam meningkatkan kualitas citra sidik jari.

1. Proses Scanning

Proses scanning citra sidik jari menggunakan mesin fingerprint HS-52 dengan memberikan tinta pada ibu jari. Scanning citra sidik jari menghasilkan ukuran 256x256 piksel grayscale dalam format bitmap. 


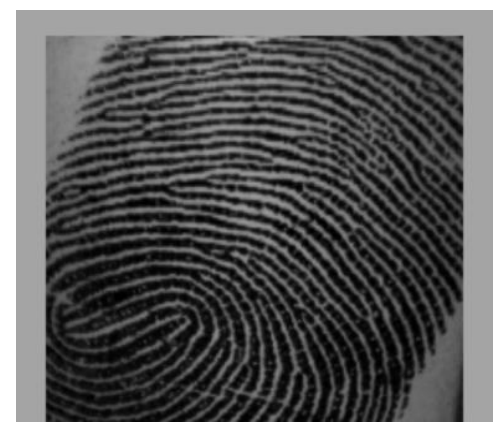

Gambar 3: Hasil Scanning Citra

\section{Proses Cropping}

Pada Gambar 3 terdapat bagian citra sidik jari yang tidak diperlukan untuk itu dilakukan proses cropping. Proses cropping menggunakan fungsi matlab imread, imcrop, imshow dan imwrite, dengan ukuran cropping 20x20 piksel.

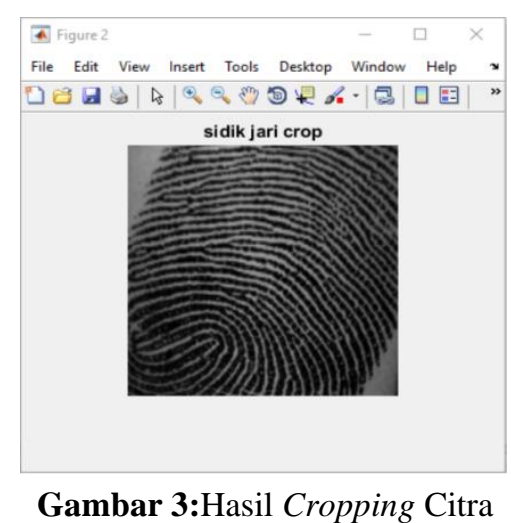

3. Proses Normalisasi

Proses normalisasi menggunakan morfologi untuk meratakan nilai intensitas menggunakan fungsi matlab imread, strel, imdilate, imshow dan imwrite

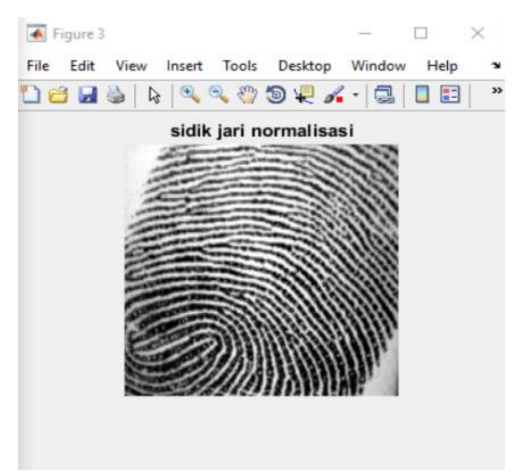

Gambar 4: Hasil Normalisasi Citra

4. Proses Filtering

Pada tahap ini citra sudah ternormalisasi dilakukan proses gabor filter untuk menghasilkan 8 citra sidik jari. Prose filter gabor menggunakan 8 arah orientasi yang berbeda, yaitu : $0^{\circ}, 22.5^{\circ}, 45^{\circ}, 67.5^{\circ}, 90^{\circ}$, $112.5^{\circ}, 135^{\circ}, 157.5^{\circ}$. Fungsi yang digunakan pada matlab adalah imread, size, subplot, imagesc, axis, mean, min, max, sin, cos, exp, normpdf, meshgrid dan imwrite 


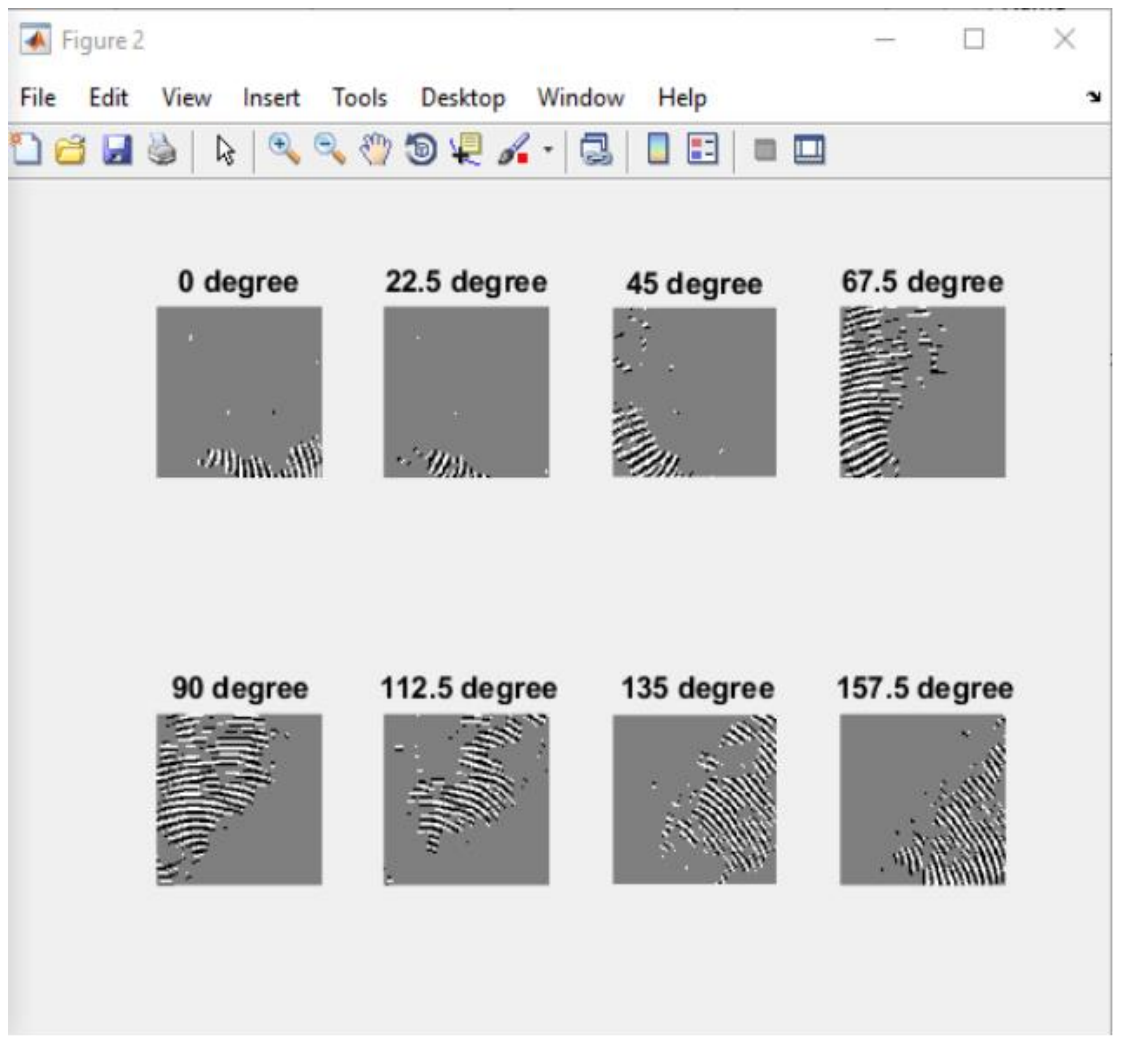

Gambar 5:Citra Gabor Filter $0^{\circ}, 22.5^{\circ}, 45^{\circ}, 67.5^{\circ}, 90^{\circ}, 112.5^{\circ}, 135^{\circ}$ dan $157.5^{\circ}$

5. Proses Ekstraksi

A. Penggabungan Citra

Hasil penggabungan citra gabor Citra Gabor Filter $0^{\circ}$, citra Gabor Filter $22.5^{\circ}$, citra Gabor Filter $45^{\circ}$, citra Gabor Filter67.5 $5^{\circ}$, citra Gabor Filter $90^{\circ}$, Citra Gabor Filter $112.5^{\circ}$, citra Gabor Filter $135^{\circ}$ dan citra Gabor Filter $157.5^{\circ}$. Fungsi matlab yang dipakai imread, imshow dan imwrite.

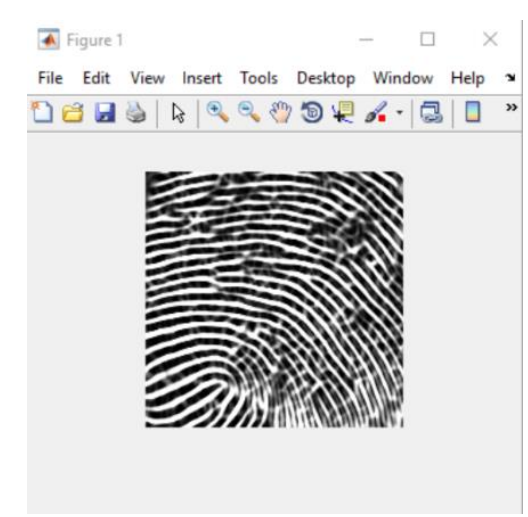

Gambar 6: Citra Hasil Penggabungan

B. Binerisasi

Hasil proses penggabungan citra sidik jari dilakukan proses binerisasi dengan nilai threshold 150 , dengan fungsi matlab imread, im $2 b w$, imshow dan imwrite. 


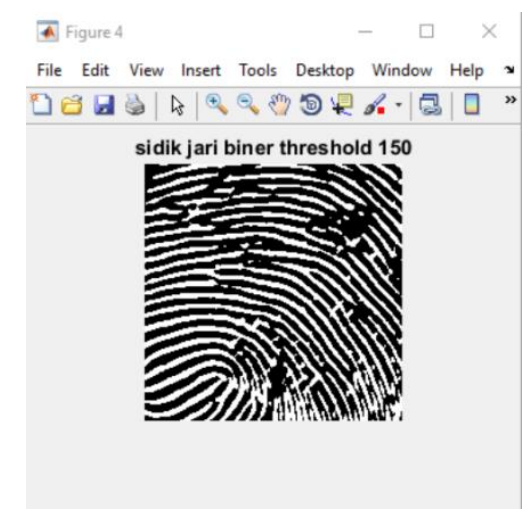

Gambar 7: Citra 1 Hasil Binerisasi

\section{Thinning}

Proses thinningdari citra binerisasi dengan menggunakan fungsi matlab imread, bwmorph, imshow dan imread dilakukan untuk menipiskan citra, sehingga nantinya citra yang dihasilkan dapat diproses baik pada tahap ekstraksi.

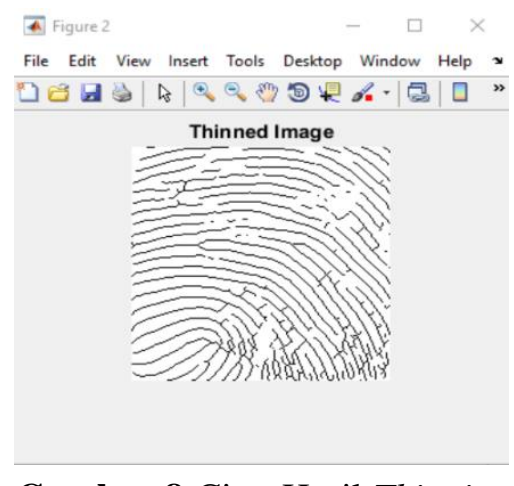

Gambar 8:Citra Hasil Thinning

D. Ekstraksi

Hasil citra thinning dilakukan proses minutae extraction untuk melihat rigde ending (termination) dan bifurcationdengan menggunakan fungsi imread, size, zeros, sum, find, length, imshow dan imwrite.

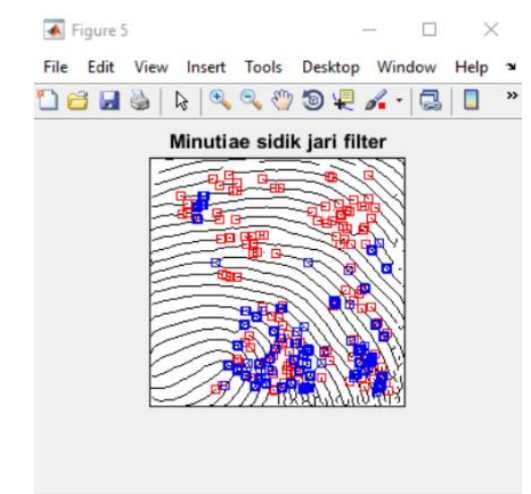

Gambar 9: Citra Hasil Minutiae Extraction 
Citra sidik jari pada Gambar 9. merupakan hasil proses minutae extractionyang sebelumnya terlebih dahulu melewati tahapan normalisasi, filtering, penggabungan, binerisasi dan thinning.Kotak berwarna merah menunjukkan rigde ending (garis terputus) dan kotak berwarna biru bifurcation (dua garis yang bertemu di salah satu ujungnya). Proses membandingkan hasil ekstraksi dengan citra pada gambar 9.

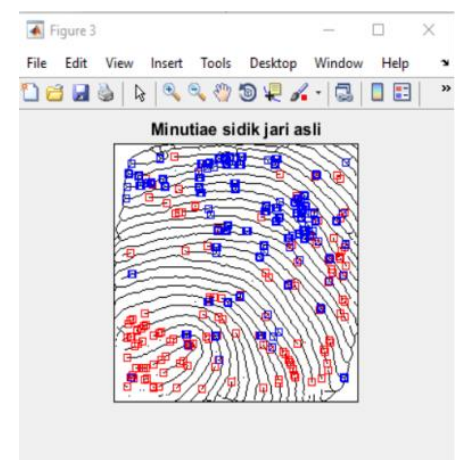

Gambar 10: Citra Hasil Minutiae Extractiondari citra asli

Ride ending dan bifurcation pada gambar 9 lebih sedikit dibandingkan gambar 10, sehingga citra sidik jari pada gambar 9 lebih jelas daripada gambar 10 .

\section{Kesimpulan}

Berdasarkan hasil dapat disimpulkan bahwa ekstraksi citra sidik jari yang dilakukan dengan tahapan cropping, normalisasi dengan morfologi, filtering denganGabor Filter dan ekstraksi dengan tahapan penggabungan, binerisasi, thinning dan Minutiae Extractiontelah dapat memperjelas garis sidik jari. Terbukti dari 10 citra yang diuji mengahasilkan ride ending dan bifurcation yang lebih sedikit dari citra aslinya, sehingga sidik jari lebih jelas dan mudah untuk dikenali

\section{Referensi}

[1] S. Guglani and E.P.S. Bhullar,"A New False Minutia Removal Based Fingerprint Identification Technique". International Journal of Advanced Research in Computer Science (IJARCS), Volume 6, Issue 6, 17-19, 2015.

[2] P.K. Bose and M.J. Kabir, "Fingerprint: A Unique and Reliable Method for Identification", Journal of Enam Medical College, Volume 7, Issue 1, 29-34, 2017.

[3] K. Cao and A.K. Jain, "Automated Latent Fingerprint Recognition”, IEEE Transactions on Pattern Analysis and Machine Intelligence, Volume 41, Issue 4, 788-800, 2019.

[4] N. Yanti, F.Z. Rachman, N. Jamal, E. Purwanto and Fachrurozy, "Jaringan Syaraf Tiruan Untuk Pengenalan Citra Sidik Jari Pada Smart”, Jurnal Teknologi Informasi dan Ilmu Komputer (JTIIK), Volume 5, Issue 5, 597-604, 2018.

[5] I.R. Wijaya, U.N. Wisesty and S.A. Faraby, "Analisis dan Implementasi Metode Gabor Filter dan Support Vector Machine pada Klasifikasi Sidik Jari”, Indonesian Journal of Computing (Indo-JC), Volume 2, Issue 2, 37-46, 2017. 
[6] N. Kahraman,Z.G.C. Taskiran andM. Taskiran, "Novel Feature Extraction Methodology with Evaluation in Artificial Neural Networks Based Fingerprint Recognition System”, Original scientific paper,Volume 1, Issue 1, 112-119, 2018.

[7] S. Chavan, P. Mundada and D. Pal, " Fingerprint Authentication Using Gabor Filter Based Matching Algorithm", International Conference on Technologies for Sustainable Development(ICTSD), Mumbai, India. Feb 04-06. DOI :10.1109/ICTSD.2015.7095910, 2015.

[8] D. Probst and J.L. Reymond, "A Probabilistic Molecular Fingerprint for Big Data Settings", Journal of Cheminformatics, 1-12, 2018.

[9] J. Santony and J. Na`am, "InfiltrateObject Extraction in X-rayImage by using MathMorphology.International Journal on Advanced Science, Engineering and Information Technology (IJASEIT)", Volume 6, Issue 2, 239-244, 2016.

[10] J. Na`am, J. Santony, Yuhandri, Sumijan and G.W. Nurchayo, "Enlarge Medical Image using LineColumn Interpolation (LCI) Method", International Journal of Electrical and Computer Engineering(IJECE), Volume 8, Issue 5, 3620-3626, 2018.

[11] P.Gayathiri,M. Punithavalli "Partial Fingerprint Recognition of Feature Extraction and Improving Accelerated KAZE Feature Matching Algorithm", International Journal of Innovative Technology and Exploring Engineering (IJITEE), Volume 8, Issue 10, 3685-3690, 2019. 